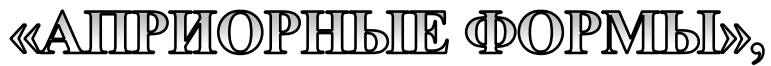

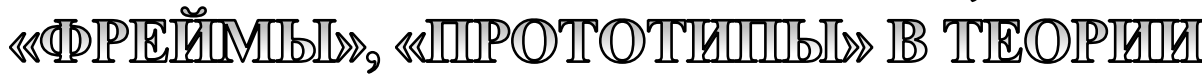

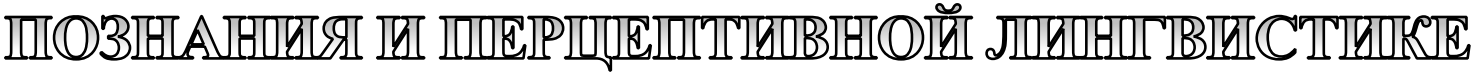

С.Д. Лобанов, Пермский федеральный исследовательский центр УрО РАН

Т.Н. Чугаева, Пермский федеральный исследовательский центр УрО РАН

А.А. Вахотин, Вятский государственный университет

Предлагается обзор некоторых теорий гносеологии, когнитивной психологии и перцептивной лингвистики. Рассматриваются понятия «априорные формы», «фреймы», «прототипы» «типизация», «категоризация», и делается вывод об универсальных и специфических свойствах при восприятии речи человеком.

Ключевые слова: априорные формы, фреймы, прототипы, типизация, категоризация, восприятие речи.

Важнейшей задачей теории познания Иммануила Канта было определить границы и возможности человеческого познания. Он признает, что источниками знания являются чувственный опыт и рациональное постижение вещей. Кант, по сути, совершил «коперниканский переворот в теории познания», т.е. обращение природы в объект активности человека. Материал природы обрабатывается посредством предшествующих опыту форм созерцания. Кант, таким образом, стал основоположником «конструктивизма» в теории познания и этики долга, основанной на свободе индивида.

Время и пространство, по Канту, - априорные формы восприятия; время внутреннего, пространство - внешнего. Единство познания осуществляется посредством трансцендентальных схем, которые связаны со сферой возможного, т.е. идеального. Эти схемы служат средством синтеза процесса познания, перехода от чувственного опыта к обобщениям, расширению познания и продуктивной способности воображения. По Канту, «в нас есть деятельная способность этого многообразного синтеза, которую мы называем воображением; его деятельность, направленную непосредственно на восприятие, я называю схватыванием [5, с. 323]». Это обстоятельство служит основой знаменитых вопросов Канта: «Что я могу знать?», «Как возможна чистая математика?», «Как возможны априорные синтетические суждения?» и т. д.

Идея активной, деятельной, упорядочивающей роли разума в восприятии была подтверждена экспериментально в конце XIX века благодаря работам выдающегося физика и офтальмолога Германа Л.Ф. Гельмгольца, представителя физиологического направления в неокантианстве, в области зрительного восприятия. Его исследования показывают, что человеческие органы чувств не механически реагируют на воздействия внешних предметов, а активно и целенаправленно формируют предмет зрительного восприятия. Воспринимая чувственный мир, мы 
всегда привносим в этот процесс нечто от нашей человеческой субъективности. По Гельмгольцу, ощущение - это знак, а не копия внешнего мира [3].

Своеобразным продолжением гносеологических идей Канта явилась феноменологическая социология Альфреда Шюца. Структуру мышления он описывает следующим образом: «Каждый шаг моего истолкования мира основывается на запасе раннего опыта, как моего собственного непосредственного опыта, так и данного мне моими сообщниками, прежде всего, моими родителями, учителями и т.д. Все эти сообщенные и непосредственные опыты включаются в определенное единство в форме моего запаса знаний, который мне служит в качестве направляющей схемы для соответствующих шагов моего истолкования мира. Все мои опыты в жизненном мире связаны с этой схемой, так что предметы и события в нем встречаются мне с самого начала в своей типичности» [18, с. 86]. Типизация, таким образом, есть искусственное «навязывание» действительности смысловой взаимосвязи. Типизация - это своего рода фильтр, с помощью которого многообразный мир в сознании сводится к простой схеме, пользуясь которой, человек поступает единообразно в типичных ситуациях. Поэтому любое истолкование мира является интерпретацией согласно известным правилам.

В теории А. Щюца язык занимает важное место. Формой «получения осадка типичных схем опыта, которые в обществе типично релевантны» [18, с. 88], является язык. В языке объективированы все возможные типизации жизненного мира. Это является основанием того, почему в феноменологической социологии языку уделяется такое внимание. «В языке общества мы становимся взрослыми. Через него опосредуются «нормальные» типизации. Поэтому я, разумеется, исхожу здесь из того, что моя типизация соответствует ти- пизации, которую принимают другие. Через язык я участвую в общественном запасе знания, в котором накапливается типичное знание» [15, с. 142]. Таким образом, согласно социологии А. Шюца, действуя, человек приобретает опыт, который, повторяясь, закладывается в некие схемы, накладываемые на воспринимаемую действительность, которая в результате интерпретируется как совокупность типичных ситуаций.

В литературе отмечается несомненная близость априорной конструкции Канта и теории фреймов Марвина Минского. Отправным моментом для теории М. Минского служит тот факт, что «человек, пытаясь познать новую для себя ситуацию или по-новому взглянуть на уже привычные вещи, выбирает из своей памяти некоторую структуру данных (образ), называемую фреймом, с таким расчетом, чтобы путем изменения в ней отдельных деталей сделать еe пригодной для понимания более широкого класса явлений и процессов. Фрейм является структурой данных для представления стереотипной ситуации» $[10$, с. 7$]$. В теории М. Минского фрейм представляется в виде сети, состоящей из узлов и связей между ними; «верхние уровни» фрейма четко определены, поскольку образованы такими понятиями, которые всегда справедливы по отношению к предполагаемой ситуации; на более низких уровнях имеется много особых вершин-терминалов или «ячеек», которые должны быть заполнены характерными примерами или данными» [10, с. 64]. Другими словами, фрейм представляет собой когнитивную структуру, состоящую из инвариантной и вариативной частей. Инвариантная часть остается неизменной и общей для всех типовых ситуаций. Вариативная часть представлена узламитерминалами, которые заполняются меняющимися параметрами с учетом вероятности данного типа ситуации. Это означает, что терминалы фрейма по умол- 
чанию заполнены наиболее типичными и частотными для данного типа ситуации данными. Применение фрейма характеризуется ожиданием от ситуации определенных характеристик, которые заложены во фрейме изначально, и ситуация воспринимается тем быстрее, чем более типичными характеристиками она обладает.

Формой существования фреймов, по М. Минскому, является язык. «Фрейм это множество вопросов, которые необходимо задать относительно предполагаемой ситуации $<\ldots>$ В чем причина этого действия (агент)? Какова цель действия (намерение)? Каковы последствия этого действия (побочные явления)? На кого (или что) это действие влияет (получатель)? С помощью каких средств оно выполнено (инструмент)?» [8, с. 129]. По мнению лингвиста В.Б. Касевича, такая интерпретация фрейма «призвана прежде всего эксплицировать познавательные процессы как таковые»; при этом он полагает, что «человеку вообще свойственно организовывать и хранить информацию в терминах фреймов. Язык - один из важнейших способов организации информации (вероятно, самый важный), поэтому есть все основания думать, что языковая система также во многом представляет собой именно систему фреймов» [6, с. 19].

Многие исследователи отмечают, что фреймы определяются не функционально, как последовательности процедур, а конструктивно, как структуры признаков, характеризующих участников, их действия и отношения между ними в конкретных ситуациях. Глубинный гносеологический смысл теории фреймов заключается в том, что фреймы представляют собой инструменты, с помощью которых человек справляется с бесконечным числом воспринимаемых стимулов, сводя их к обобщенным, стереотипным объектам и ситуациям. Фрейм представляется как априорную конструкцию, интерпретирующую действительность, производя- щую ее типизацию. Операция типизации позволяет рассматривать объект как типичный и, следовательно, предсказуемый в своем поведении. Таким образом, познание мира во многом основывается на запасе знаний, приобретенных в прошлом. При этом опыт проходит некоторую обработку и закладывается в виде априорных структур, которые при необходимости извлекаются из долговременной памяти. Все многообразие объектов мира (действия, рассуждения, зрительные и акустические образы и т.д.), таким образом, через процедуры аппроксимации или типизации, сводится к неким обобщенным схемам. Это позволяет познающему субъекту игнорировать несущественные для восприятия детали и тем самым экономично и эффективно преобразовывать мир в «доверяемую действительность» («vertraute Wirklichkeit» по А. Щюцу).

На современном этапе развития науки считается, что объект воспринимается не как сумма отдельных элементов, как считали представители структурализма, а целиком, как гештальт. Под гештальтом понимается нечто «целое, неразлагаемое на части и не сводимое к сумме частей» $[13$, с. 88$]$. Восприятие гештальта происходит путем сличения воспринимаемого облика с эталоном, хранящимся в долговременной памяти на основании существенных признаков, характеризующих объект как целостное единство. Необходимость оперирования не всеми элементами образа, а лишь частью признаков облегчает механизм восприятия и делает его экономичным и быстрым. «При распознавании входящей информации человек справляется с ней не путем исчерпывающей обработки поступающего сигнала, а на основе выбрасывания несущественной информации» [13, с. 92]. Минимально необходимый набор признаков носит название порога восприятия, который является относительным и количество необходимой информации может 
сокращаться или увеличиваться в зависимости от условий восприятия, контекста и состояния субъекта, что находит отражение в различных стратегиях восприятия [13, с. 89].

В современной науке считается доказанным, что наличие эталона в долговременной памяти и его качественные характеристики оказывают значительное влияние на результат восприятия. Буквальная интерпретация понятия эталон предполагает, что «опознание возможно только тогда, когда между «внешним» объектом и его «внутренней» репрезентацией имеется соответствие $1: 1$, это значит, что даже при незначительном расхождении между объектом и его эталоном опознания не произойдет» [12, с. 150]. Строгое следование этой теории означало бы необходимость формирования огромного количества эталонов, соответствующих каждой из разнообразных воспринимаемых форм.

В современных когнитивных науках эта задача решается обращением к понятию прототипа. Под прототипом понимается «абстракция набора стимулов, воплощающая множество сходных форм одного и того же паттерна» [12, с. 147]. Это наиболее типичный представитель данного типа объектов, обладающий наиболее частотными инвариантными признаками объектов данного типа. Как и априорные формы, прототипы формируются под влиянием опьыта и служат одной из форм его объективации и актуализации при восприятии.

С понятием прототипа тесно связано понятие категории. Принято считать, что процесс восприятия во многом является процессом категоризации. Другими словами, воспринимающий субъект относит воспринимаемый предмет к определенной группе, классу предметов и обобщает его в слове, то есть к некоторой категории. Таким образом, в процессе восприятия предполагается категоризация. Категоризация является естественной гносеологиче- ской потребностью, условием восприятия действительности. Как утверждает P.М. Фрумкина, «врожденной потребностью высокоразвитого организма является не просто сжатие бесконечного многообразия мира, но сжатие с целью упорядочения и нахождения закономерностей» [13, с. 89].

В сознании человека категория представлена прототипом, сочетающим в себе наиболее типичные и характерные признаки. Прототип рассматривается как «лучший представитель («лучший пример») когнитивной или языковой категории»; отнесенность данного объекта определенной категории определяется соответствием его ключевых признаков признакам прототипа, степенью его отдаленности от прототипа [9, с. 167]. Например, в мире существует бесконечное количество кружек, разнообразие цвета и форма которых бесконечны, однако восприятие объекта и отнесение его к классу кружек требует анализа его признаков и соотнесения с некоей абстрактной усредненной кружкой. Каким оригинальным ни был бы воспринимаемый предмет, когнитивный аппарат категоризует его, обобщая и сводя все ее разнообразие к набору инвариантных признаков - к «прототипическому» предмету, представителю данной категории. Таким образом, термин категоризация, как он понимается в когнитивной науке, пересекается с термином типизация, введенным А. Шюцем.

Как и фреймы, прототипы являются инструментами, с помощью которых человек справляется с восприятием бесконечного количества воспринимаемых стимулов, поставляемых действительностью» [19, с. 38$]$. В результате восприятия и категоризации создается «прототипический» мир, состоящий из знакомых, «доверяемых» объектов. Бесконечное многообразие мира сводится к некоторым простым схемам, позволяющим экономно, благодаря реализации в них ключевых характеристик, постигать действительность. 
Понятие «прототипический мир» схоже с тем, что понимал А. Щюц под «доверяемой действительностью», в которую, согласно его теории, человек стремится превратить всю многообразную действительность при ее восприятии.

Будучи одной из сторон когнитивной деятельности человека, восприятие речи c неизбежностью подчиняется универсальным законам, обнаруживая при этом специфические особенности обсуждаемых понятий в процессах восприятия речи человеком. Сложность и многоаспектность процессов восприятия речи требуют дальнейшего рассмотрения.

Несмотря на большое количество фундаментальных работ, представляющих различные модели восприятия речи, единства взглядов на закономерности перцептивных процессов до сих пор не достигнуто и разработка единой, обладающей исчерпывающей объяснительной силой теории восприятия остается делом будущего.

Спорными остаются многочисленные кардинальные теоретические вопросы, вызывающие разногласия среди исследователей, в том числе: каким образом осуществляется категоризация единиц восприятия? в каком именно виде звуковой облик слова представлен в языковом механизме, и каким образом слушающий сохраняет как единое целое все возможные звуковые образы словоформы; существует ли независимый от других уровней механизм распознавания слова, либо он включен в «сквозной» процесс распознавания «сверху вниз» и «снизу вверх» и многие другие.

В. Зендлмайер строит свою модель восприятия речи на основании фонетических «ментальных репрезентаций слов» в сознании человека, которые не только являются результатом процесса восприятия, но и осуществляют контроль за восприятием речи $[17$, с. 68$]$. Различные лингвистические уровни репрезентация одновременно доступны слушающему, и он актуализирует уровень, наиболее эффективный для распознавания речевой единицы в конкретных условиях, т.е. стратегии варьируются в зависимости от перцептивной задачи.

Таким образом, В. Зендлмайер справедливо полагает, что в процессе распознавания слушающий воссоздает прототип (идеальный тип) того или иного звука из всех тех его репрезентаций, которые он когда-либо слышал. Если допустить, что различные по длине фонетические единицы, вплоть до слова, представлены в форме прототипов, следует признать, что для этого требуется огромный объем долговременной памяти. В. Зендлмайер утверждает, что материальная основа аналоговых репрезентаций в форме прототипов может быть рассмотрена в терминах нейрофизиологических коррелятов спектральных эталонов, поскольку общеизвестно, что входящая звуковая волна подвергается частотному анализу периферийной системы слуха [17, с. 70]. В таком виде понимание единиц восприятия соотносится с теориями прототипов (Дж. Лакофф, Т. Гивон, Р. Лангаккер, Е.С. Кубрякова, В.З. Демьянков и др.), понятием матрицы «идеальных типов» М. Вертхаймера или системы «прообразов» Э. Рош.

Другим примером может служить перцептивная модель с использованием логики размытых множеств Д. Массаро, в которой считается, что каждый слог представлен в памяти определенным прототипом. Под прототипом автор понимает перцептивную единицу (или категорию) соответствующего языка, складывающуюся из суммы признаков и показателей степени соответствия признаков «идеальным» представителям данной категории [16, с. 219].

Гипотеза перцептивного эталона предполагает, что в памяти носителя языка каждой фонеме соответствует свой перцептивный эталон (слуховой образ, хранящийся в памяти, который понимается как 
определенная конфигурация полезных акустических признаков [7, с. 260]. Как отмечают С. Кодзасов и О.Ф. Кривнова, вместо понятия перцептивного эталона может использоваться понятие перцептивного прототипа фонемы с близким содержанием. Считается, что в качестве перцептивной модели человек может использовать «прототипические образы двух типов: усредненный перцептивный образ (или обобщенный звуковой тип), который формируется в памяти в результате усреднения разных реализаций одной и той же фонемы, и статистически представительный периептивный образ, когда в памяти в качестве прототипа фиксируется наиболее часто встречающаяся конфигурация слуховых признаков фонемы» [7, с. 261].

Таким образом, одновременно ставятся две важных проблемы: вероятностной организации перцептивных образов в сознании слушающего, как целостной системы включенных в неё единиц (фонем, слогов, слов и синтаксических структур), которая, в свою очередь, соотносится с общими проблемами языковой категоризации и инвариантности/вариативности.

Как отмечает А.В. Бондарко, «идея инвариантности/вариантности и "прототипический подход” закономерно и естественно интегрируются в единой системе лингвистического анализа» [1, с. 187]. Причина общности обсуждаемых концепций с точки зрения принципов «центр-периферия - постепенные переходы - частичные пересечения», «полевая структура» и «прототипы и их окружение», по мнению А.В. Бондарко, «коренится в глубинных свойствах изучаемых объектов, в самом предмете исследования и лингвистического описания» [1, с. 192]. Представление о перцептивной базе языка как системе вероятностно организованных фонетических типов и прототипов слов укладывается в рамки такого подхода.

В контексте продолжающейся дискуссии о моделях восприятия речи, с нашей точки зрения, не утрачивает актуальности системное представление о перцептивной базе языке, которое оказывается созвучным идеям современных теорий восприятия речи человеком, обладая значительной объяснительной силой как в концептуальных, так и в процедурных вопросах. Экспериментально подтверждается психологическая реальность теории перцептивной базы языка, введенной в лингвистический обиход 3.Н. Джапаридзе, как «языковой системы средств восприятия звучания речи» или как «единство хранящихся в памяти человека эталонов фонетических единиц и правил сравнения с ними» [4, с. 4]. Перцептивная база рассматривается как иерархическая структура языковых единиц, отражающая многоуровневость языка.

Принципиально важен тезис о зонной природе эталонов ПБ языка и категориальности восприятия фонетических единиц, что хорошо согласуется с современными представлениями психологии. Зонный характер описывается как восприятие разных реализаций одного и того же звука, оцениваемых идентично; например, восприятие гласного в ударной и безударной позиции, произнесенного разными людьми, разными голосами, в разном темпе и громкости, изолированно или в связном тексте. Зонный характер эталонов и определяется категориальностью восприятия, которая, в свою очередь, обусловлена специфической системой конкретного языка. Кроме того, такой подход позволяет выявить группы слов, которые можно рассматривать как фонетические типы слов конкретного языка и, таким образом, позволяет описать звуковой облик языка в единстве его существенных языковых характеристик [14, с. 25].

Акустические и фонетические характеристики слова, разумеется, не являются идеальными, стабильными и единообразными; вариативность фонетического облика языковых единиц безгранична. Тем 
не менее речь даже в довольно сложных условиях бывает понята, а слова идентифицированы. Такая устойчивость перцептивного механизма объясняется участием в данном процессе априорных форм.

При восприятии речи слушающий не устанавливает полное соответствие полученной информации с хранящимся в памяти эталоном, поскольку в перцептивной базе представлены не столько эталоны фонетических обликов слов, сколько их прототипы и любой акт восприятия слова является актом аппроксимации и типизации его фонетического облика. Субъективные факторы, такие как индивидуальные особенности произношения, а также объективные помехи среды при этом игнорируются.

Кроме того, при восприятии важную роль играют процессы вероятностного прогнозирования, основанного на учете информации более высоких языковых уровней. Перцептивный механизм слушающего характеризуется наличием стратегий восприятия и способности ими гибко оперировать; между процессами «снизу-вверх» и «сверху - вниз» происходит постоянное взаимодействие и взаимовлияние.

В зависимости от условий восприятия «детализация» механизма может меняться. Например, при восприятии незнакомого слова или при восприятии речи в затрудненных условиях оперативными единицами могут служить и слоги, и фонемы, и даже дифференциальные признаки. Однако при восприятии знакомого текста оперативными единицами могут служить целые слова, словосочетания и даже предложения. Например, в одном из экспериментов Е.И. Риехакайнен абсурдное с точки зрения смысла сочетание «свечка говорит» не было воспринято верно ни одним испытуе- мым, зато в 33,3\% случаев заменялось на словосочетание «свечка горит» [11, с. 17].

Данное явление Дж. Брунер называл «перцептивной готовностью» или «готовностью категории», под которой он понимал преднастроенность механизма к восприятию определенного объекта» [2, с. 121]. При этом он отмечал, что чем выше эта «перцептивная готовность», тем меньше необходимо признаков для опознания. При восприятии речи зачастую фонетический облик слов бывает искажен до неузнаваемости (ср.: [с’т’ъ], [грът]). Однако, благодаря типизации, слушающий может не замечать этого несоответствия и без труда понимает сказанное. Очевидно, при восприятии речи в типичных условиях субъект, принимая решение, опирается не столько на объективные характеристики объекта, сколько на некоторые конструкции (прототипы, фреймы), имеющиеся в долговременной памяти, позволяющие ему реконструировать искаженные или отсутствующие элементы, а также сформировать ожидания и прогнозировать («симулировать») восприятие других элементов.

Таким образом, при рассмотрении ряда понятий различных философских и лингвистических теорий, в том или ином аспекте моделирующих восприятие объекта (категоризация, типизация, фреймы, прототипы, эталоны перцептивной базы), становится очевидным, что универсальная их функция в процессе восприятия речи сводится к функции промежуточных элементов, «конструкций ума, накладываемых» на воспринимаемые объекты и облегчающих процесс их восприятия посредством упорядочения и нахождения закономерностей.

\section{Библиографический список}

1. Бондарко A.B. Центр-периферия, полевые структуры, прототипы и их окружение // Теоретические проблемы языкознания: Сборник статей к 140-летию кафедры общего языкознания филологического факультета С.-Петербургского государственного университета / гл. ред. Л.А. Вербицкая. - СПб.: Филологический факультет, 2004. - 656 с.

2. Брунер Дж. О перцептивной готовности // Хрестоматия по общей психологии. Вып. III. Субъект познания. - М.: Российское психологическое общество, 1998. - 515 с. 
3. Гельмгольи Г. О восприятии вообще // Психология ощущений и восприятия / ред. Ю.Б. Гиппенрейтер и др. - изд. 2-е, испр. и доп. - М.: «ЧеРо», 2002. - 610 с.

4. Джапаридзе 3.Н. Перцептивная фонетика: основные вопросы. - Тбилиси: Мецниереба, 1985. - 118 с.

5. Кант И. Критика способности суждения. / Соч. в 6 т. - Т. 5. - М., 1966. - 564 с.

6. Касевич В.Б. Семантика. Синтаксис. Морфология. - М.: Наука, 1988. - 312 с.

7. Кодзасов С.В., Кривнова О.Ф. Общая фонетика. - М.: РГГУ, 2001. - 592 с.

8. Кулаков Ф.М. Приложение к русскому изданию // Минский М. Фреймы для представления знаний. М: Энергия, 1979. - 153 с.

9. Лангаккер Р.В. Модель, основанная на языковом употреблении / пер. с англ. // Вестн. Моск. ун-та. Сер.9: Филология. - 1997. - № 4. - С. 159-174.

10. Минский М. Фреймы для представления знаний. - М: Энергия, 1979. - 153 с.

11. Риехакайнен Е.И. Взаимодействие контекстной предсказуемости и частотности при восприятии спонтанной речи: автореф. дис... канд. филол. наук. - СПб., 2010. - 27 с.

12. Солсо Р. Когнитивная психология. - 6-е изд. - СПб.: Питер, 2006. - 589 с.

13. Фрумкина Р.М. Психолингвистика: учеб. для вузов. - М.: Академия, 2008. - 336 с.

14. Чугаева T.Н. Звуковой строй языка в перцептивном аспекте (экспериментальное исследование на материале английского языка): автореф. дис... д-ра филол. наук. - СПб., 2009. - 47 с.

15. Шюи А. Возвращающийся домой // Социологические исследования. - 1995. - № 2. - С. 139-142.

16. Massaro D. Psychological aspects of speech perception: implications for research and theory. // Handbook of psycholinguistics / ed. by M.N. Gernsbacher - San Diego etc: Academic Press, 1994. - P. 219-263.

17. Sendlmeier W.F. A model for the phonetic mental representation of words // Proceedings XIth ICPhS. Tallinn, - 1987. - Vol. 1. - 397 c.

18. Schutz A., Luckmann Th. Die Strukturen der Lebenswelt, 2 vols. - Neuwied: Luchterhand, 1975. Bd. I. I цит.: по Абельс X. Интеракция, идентичность, презентация. Введение в интерпретативную социологию. - СПб.: Алетейя, 2000. - 272 с.

19. Verschueren J. Metapragmatics and universals of linguistic action // Linguistic action: Some empirical conceptual studies / ed. by J. Verschueren - Norwood (N.J.), 1987. - P.125-140. / цит. по: Структуры представления знаний в языке /отв. ред. Е.С. Кубрякова. - М.: ИНИОН РАН, 1994. - С. 38-77.

\title{
«A PRIORI FORMS», «FRAMES», «PROTOTYPES» IN EPISTEMOLOGICAL THEORIES AND SPEECH PERCEPTION THEORIES
}

\author{
S.D. Lobanov ${ }^{1}$, T.N. Chugaeva ${ }^{1}$, A.A. Vakhotin ${ }^{2}$ \\ ${ }^{1}$ Perm Federal Research Centre UB RAS \\ ${ }^{2}$ Vyatka State University
}

The article offers an overview of some theories of epistemology, cognitive psychology and perceptual linguistics. The concepts of «a priori forms», «frames», «prototypes», «categorization» are considered and the conclusion follows concerning universal and specific properties of human speech perception.

Keywords: a priori forms, frames, prototypes, categorization, human speech perception.

\section{Сведения об авторах}

Лобанов Сергей Дмитриевич, доктор философских наук, профессор кафедры иностранных языков и философии, Пермский федеральный исследовательский центр УрО РАН. 614990, г. Пермь, ул. Ленина, 13a; e-mail: sdl-grey54@ @andex.ru

Чугаева Татьяна Николаевна, доктор филологических наук, заведующая кафедрой иностранных языков и философии, ПФИЦ УрО РАН; e-mail: tatiananch@mail.ru

Вахотин Антон Андреевич, аспирант кафедры лингвистики и перевода, Вятский государственный университет (ВятГУ), 610000, г. Киров, ул. Московская, 36; e-mail: samo87@ mail.ru 